\title{
Prevalence and Risk Factors of Eye Problems Among Older People in Central Tropical Region, Naypyitaw Union Territory, Myanmar
}

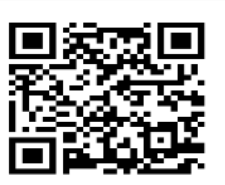

\section{KYAW KO KO', TEPANATA PUMPAIBOOL*1, MAUNG MAUNG MYO WYNN², YE WIN², PYAE LINN AUNG', TIN MOE KYI}

PURPOSE: Vision is essential one and it is proximately linked with quality of life. In the meantime, older populations are increasing rapidly in the whole world and thus, age-related macular degeneration, glaucoma, cataract and diabetic retinopathy are becoming common. Hot and dusty environment, inadequate access to water and poor facial hygiene are risk factors for blindness.

MATERIALS AND METHOD: Lewe Township was purposively selected due to its high prevalence of eye problems. A cross-sectional study was conducted and simple random sampling was applied to achieve desired sample size. The structured questionnaires were used to collect data including screening of eye problems from 414 elderly population. Frequency, percentage, mean, SD and other descriptive analysis were determined and chi-square test for associations was constructed.

RESULTS: Cataract was the highest prevalence rate with $40.8 \%$ followed by refractive error (27.3\%) and pterygium (12.8\%) among older people population in research area. While knowledge level indicated good level $(88.4 \%)$, good attitude level (21.3\%) and good practice level $(\mathbf{2 7 . 1} \%)$ were noticeably low among older people. In the meantime, there were significant associations between age ( $\mathrm{p}=0.003)$ and education level $(\mathrm{p}=0.001)$ with knowledge level of older people while age $(\mathrm{p}=0.001)$, education level $(\mathrm{p}<0.001)$, occupation $(\mathrm{p}=0.038)$ showed statistically association with attitude level.

CONCLUSION: The study noticed that higher prevalence of eye problems with relatively poor level of eye care seeking practice and unawareness on risk factors in targeted community. Knowledge and awareness for changing attitude about eye problems, eye care seeking behaviour and preventive practices should be accomplished more.

KEYWORDS: Eye problems, Prevalence, Risk Factors, Older People, Myanmar

\section{INTRODUCTION}

Nowadays around the world, eye diseases are widespread. According to the World Health Organization, the most important three eye diseases or conditions that are a potential threat to the high and industrialized countries' population are diabetic retinopathy, glaucoma, and age-related macular degeneration. In the other hand, for middle and lowincome countries, cataract is responsible for major cause of blindness and visual impairment. One more vital reason for visual harm is refractive errors. Some of the important reasons for vision loss or low vision are age, access to healthcare, healthcare facilities, gender, genetic problems and the prevalence of family history. ${ }^{1}$

For the whole nation of Myanmar, total population is 59 million and 6o years and above is 5.23 million in the year of 2014.The proportion of elderly population (over 6o years) was 8.8 percent in the same year and according to UN projections, by 2030 it will increase to $15 \%$ of the population, and by 2050 older people will consist of a quarter of Myanmar's total population. Shortly after 2035, persons aged 60 and older will be more than children under age $15 .^{2}$
According to the data from Rapid Assessment of Avoidable Blindness Survey, Myanmar in 2018, prevalence of blindness is 2.9\%. Prevalence of severe visual impairment is $3.4 \%$. Cataract blindness is $72.9 \%$ and severe cataract visual impairment is $86.4 \%$. The other major causes of blindness were glaucoma $(11.7 \%)$, corneal opacity $(2.9 \%)$, surgical complications (2.3\%), trachoma (1.6\%) and diabetic retinopathy $(0.9 \%)$. Other major cause of visual impairment was uncorrected refractive error (21.1\%). ${ }^{3}$ According to the climate condition of Myanmar, hot, dry and dusty environment and inadequate access to water and facial hygiene are also risk factors for being blindness. ${ }^{4}$ The elderly care, as one of the target population in Myanmar, was aimed to promote active and healthy aging by the elderly health care project of ministry of health since 1992-93. This program is based on comprehensive health care: promotive, preventive, curative and rehabilitative care. ${ }^{5}$

In Myanmar, increasing age plays as a major risk factor for blindness, visual impairment, cataract, glaucoma and trachoma. Roughly one person in three has some form of vision-reducing eye disease by the 
age of 65 . Causes of eye diseases can be hypothesized as many factors and the most common are smoking, alcohol consumption, diet and ageing. ${ }^{6}$ Other risk factors may include a family history of an eye disease; certain lifestyle behaviors (for example, working under direct sunlight); the presence of disease biomarkers, such as druse in the case of Age-Related Macular Degeneration; high intraocular pressure in the case of glaucoma; or diabetes in the case of diabetic retinal disease. ${ }^{7}$ There are certainly many areas that endure with poor vision or remain blind due to lack of access to basic eye care services. It was more preferably in rural area than urban counterparts that very high rates of visual impairment in Myanmar and northern India. ${ }^{2-8}$

Knowledge and awareness about eye diseases, health seeking behavior and preventive practices should be accomplished in the community and the consequence should be reviewed and applied to empower people. Since health seeking behavior is essential in encountering blindness, not understanding about the nature of disease, where to look for health care and not knowing to take preventive measures get worse the disease condition and threaten the community. Thus, this crosssectional study was organized to explore the basic characteristics associated with eye problems among older people living in rural area of Lewe Township, Naypyitaw Union Territory, Myanmar.

\section{MATERIALS AND METHOD}

Lewe township was purposively selected as it is high prevalence township for eye problems among other townships in Naypyitaw and older people ratio is relatively high. From among the 261 villages of Lewe, 5 villages (Kunchan village, Kyarinn village, Aunggone village, Thabyaypin village and Sharchaung village) with highest older people population were chosen. The sample size was calculated by using one population proportion formula ${ }^{9}$ with the reference value of proportion of people who have cataract from Rapid Assessment of Avoidable Blindness Survey, Myanmar in $2018^{3}$ and 414 older people who aged 50 years and above and can communicate very well were recruited by systemic random sampling based on a list provided by the local administrative unit and interviewed via structured questionnaires and made eye care screening using ophthalmoscope by ophthalmologist. The standard questionnaire forms in English language were produced with reference from WHO cataract survey questionnaires and previous relevant surveys and reviewed by two experts from Prevention of Blindness and Trachoma Control Programme, Naypyitaw, Myanmar. Back-translation methods were used for rendering responses into Burmese. Pre-test was done with thirty respondents in another similar villages of Lewe township (Naungbo village and Alar village). Cronbach's Alpha coefficient of the questionnaires was calculated for reliability in knowledge and attitude part of questionnaire, resulting 0.722. KuderRichardson formula 20 (KR2o) was measured to test the internal consistency of the questions with dichotomous choices as satisfactory. The majority of questions are entitled as single or multiple response with predefined choices. The information covered general characteristics for each resident together with risk factors for eye problems, knowledge, attitude and practice regarding prevention of eye problems.

The data-collection process was carried out in all selected villages during September 2018. The research team was set up with one ophthalmologist from 200Bedded hospital, Pyinmana township and two health assistants from Prevention of Blindness and Trachoma control Programme, Pyinmana township. Those health assistants were trained by the researcher for one day so as to understand the questionnaires, data-collection process, practicing under real conditions, and human ethics. The data collectors were also requested to explain the questionnaire clearly to the respondents and not to prompt correct answers to avoid bias. Collected data were coded and entered by using Epi-data 3.1 and transferred to STATA version 13.0 and analyzed. Frequencies, proportions, and mean and standard deviation were used to describe the descriptive statistics and mean value were used to categorize knowledge, attitude and practice level. Chi-square test and correlation were used to illustrate associations. Statistical significance was set at 0.05 . Ethical approval for this study was submitted and approved by the Ethics Review Committee on Medical Research involving Human Subjects, Department of Medical Research, Ministry of Health and Sports (Approval Number Ethics/DMR/2018/144). The respondents can decide voluntarily for participation in the study after the interviewer explained the objectives of the study and obtained informed consent from the respondents. 


\section{RESULTS}

Among 414 participants, majority of respondents were between 50-65 years $(57.7 \%)$, female $(65 \%)$, married (6o.6\%), with primary level of education $(53.9 \%)$, farmers $(42.5 \%)$, with less than 5 household members (61.4\%) and possess monthly family income of less than 500,000 Kyats (62.8\%) respectively. (Table 1)

\begin{tabular}{|c|c|c|}
\hline CHARACTERISTICS & FREQUENCY & PERCENTAGE \\
\hline \multicolumn{3}{|l|}{ AGE (YEARS) } \\
\hline $50-65$ & 239 & $57 \cdot 7$ \\
\hline$>65$ & 175 & 42.3 \\
\hline \multicolumn{3}{|l|}{ SEX } \\
\hline Male & 145 & 35.0 \\
\hline Female & 269 & 65.0 \\
\hline \multicolumn{3}{|l|}{ MARITAL STATUS } \\
\hline Single & 49 & 11.9 \\
\hline Married & 251 & 60.6 \\
\hline Widow & 104 & 25.1 \\
\hline $\begin{array}{c}\text { Separate/ } \\
\text { divorce }\end{array}$ & 10 & 2.4 \\
\hline \multicolumn{3}{|c|}{ EDUCATION LEVEL } \\
\hline Illiterate & 50 & 12.1 \\
\hline Primary & 223 & 53.9 \\
\hline Secondary & 70 & 16.9 \\
\hline High school & 25 & 6.0 \\
\hline Graduated & 9 & 2.2 \\
\hline Others $^{*}$ & 37 & 8.9 \\
\hline \multicolumn{3}{|l|}{ OCCUPATION } \\
\hline House work & 113 & $27 \cdot 3$ \\
\hline Farmer & 176 & 42.5 \\
\hline Retired & 6 & 1.5 \\
\hline Labour & 65 & $15 \cdot 7$ \\
\hline $\begin{array}{c}\text { Unemployme } \\
\text { nt }\end{array}$ & 18 & $4 \cdot 3$ \\
\hline Others $^{* *}$ & 36 & 8.7 \\
\hline \multicolumn{3}{|c|}{ HOUSEHOLD MEMBERS } \\
\hline$<5$ & 254 & 61.4 \\
\hline$\geq 5$ & $16 o$ & 38.6 \\
\hline \multicolumn{3}{|c|}{ MONTHLY FAMILY INCOME } \\
\hline $\begin{array}{l}<500,000 \\
\text { Kyats }^{* * *} \\
\end{array}$ & 260 & 62.8 \\
\hline $\begin{array}{l}\geq 500,000 \\
\text { Kyats }\end{array}$ & 12 & 2.9 \\
\hline $\begin{array}{l}\text { Do not want } \\
\text { to answer }\end{array}$ & 142 & $34 \cdot 3$ \\
\hline \multicolumn{3}{|c|}{$\begin{array}{l}\text { Table 1. General characteristics of } 414 \text { respondents } \\
\text { (*Monastery school education: }{ }^{* *} \text { Own business and } \\
\left.\text { traders: }{ }^{* * *} \text { USD } \sim 1550 \text { Kyats }\right)\end{array}$} \\
\hline
\end{tabular}

Risk factors for eye problems were explored among 414 older people and the results indicated that $45 \%$ of older people had underlying diseases and among them, hypertension was highest prevalence with $51.1 \%$, $53.9 \%$ had excessive sunlight exposure, $20.5 \%$ were smoking, $27.5 \%$ had previous history of eye injury, and $6.3 \%$ had alcohol drinking history. (Table. 2)

\begin{tabular}{|c|c|c|}
\hline RISK FACTORS & FREQUENCY & PERCENTAGE \\
\hline \multicolumn{3}{|c|}{ UNDERLYING DISEASES } \\
\hline $\begin{array}{c}\text { Cardiovascular } \\
\text { disease }\end{array}$ & 12 & 2.9 \\
\hline $\begin{array}{c}\text { Cardiovascular } \\
\text { disease+ Diabetes } \\
\text { + Hypertension } \\
\end{array}$ & 1 & 0.2 \\
\hline Diabetes & 21 & 5.1 \\
\hline $\begin{array}{c}\text { Diabetes + } \\
\text { Hypertension }\end{array}$ & 13 & 3.1 \\
\hline Hypertension & 95 & 22.9 \\
\hline Cancer & 3 & 0.7 \\
\hline Others $^{*}$ & 41 & 9.9 \\
\hline $\begin{array}{l}\text { No underlying } \\
\text { diseases }\end{array}$ & 208 & 50.2 \\
\hline Did not know & 20 & 4.8 \\
\hline $\begin{array}{l}\text { Excessive sunlight } \\
\text { exposure }\end{array}$ & 223 & 53.9 \\
\hline Smoking & 85 & 20.5 \\
\hline $\begin{array}{c}\text { History of Injury } \\
\text { to eyes }\end{array}$ & 114 & 27.5 \\
\hline Alcohol Drinking & 26 & 6.3 \\
\hline
\end{tabular}

Table 2. Risk factors for eye problems of 414 older people (*Joint pain, headache and muscular pain)

Regarding knowledge, attitude and practice related with eye problems after categorizing into groups based on mean scores ( $\geq$ Mean is Good level and $<$ Mean is poor level), the results showed that $88.4 \%$ of older people had good level of knowledge on eye problems meanwhile $78.7 \%$ had poor attitude on eye problems. These effects can also be seen in practice score as only $\mathbf{2 7 . 1} \%$ of older people seek eye care for their eye health (Table 3 ).

\begin{tabular}{|c|c|c|}
\hline DESCRIPTION & FREQUENCY & PERCENTAGE \\
\hline OVERALL KNOWLEDGE & \\
\hline Good & 366 & 88.4 \\
\hline Poor & 48 & 11.6 \\
\hline OVERALL ATTITUDE & & \\
\hline Good & 88 & 21.3 \\
\hline Poor & 326 & 78.7 \\
\hline OVERALL PRACTICE & & \\
\hline Good & 112 & 27.1 \\
\hline Poor & 302 & 72.9 \\
\hline
\end{tabular}

Table 3. Overall level of knowledge, attitude and practices regarding eye problems $(n=414)$ ( ${ }^{*}$ Grouping by mean scores) 
According to the screening results by ophthalmologist, the prevalence of eye problems is significantly high among rural older people population. Cataract is the highest one as $40.8 \%$ of older people suffer this followed by refractive error $(27.3 \%)$ and pterygium (12.8\%) (Table 4 ).

\begin{tabular}{|c|c|c|}
\hline DESCRIPTION & FREQUENCY & PERCENTAGE \\
\hline EYE PROBLEMS & 169 & 40.8 \\
\hline $\begin{array}{c}\text { Cataract } \\
\text { Refractive }\end{array}$ & 113 & 27.3 \\
\hline $\begin{array}{c}\text { Pterygium } \\
\text { Corneal } \\
\text { opacity }\end{array}$ & 53 & 12.8 \\
\hline Epiphora & 9 & 3.6 \\
\hline Glaucoma & 8 & 2.2 \\
\hline $\begin{array}{c}\text { Corneal ulcer } \\
\text { Conjunctivitis }\end{array}$ & 4 & 1.9 \\
\hline $\begin{array}{c}\text { Optic nerve } \\
\text { atrophy }\end{array}$ & 3 & 0.9 \\
\hline $\begin{array}{c}\text { Retinitis } \\
\text { pigmentosa }\end{array}$ & 1 & 0.7 \\
\hline $\begin{array}{c}\text { No eye } \\
\text { problem }\end{array}$ & 36 & 0.7 \\
\hline
\end{tabular}

Table 4. Prevalence of eye problems $(n=414)$
Table 5 described that there were significant associations between age $(\mathrm{p}=0.003)$ and education level $(\mathrm{p}=0.001)$ with knowledge level of older people while age $(\mathrm{p}=\mathrm{o.001})$, education level $(\mathrm{p}<\mathrm{o.001})$, and occupation $(\mathrm{p}=\mathrm{0.03} 8)$ showed statistically association with attitude level. Conversely, there were no associations with assembled variables and practice level at p-value $<0.05$.

Table 6 showed that there was a significant association between smoking $(\mathrm{p}=0.026)$ and presence of eye problems while other risk factors have no significant associations with presence of eye problems at $\mathrm{p}$-value $<0.05$.

Table 7 described that there were no significant associations between knowledge, and attitude, and presence of eye problems at p-value $<0.05$. However, practice level was significantly associated with presence of eye problems at $\mathrm{p}$-value $=0.039$.

Lastly, table 8 illustrated the correlations among knowledge, attitude and practice. There were positive association between knowledge and attitude, and knowledge and practice. Yet, there were no

\begin{tabular}{|c|c|c|c|c|c|c|c|c|c|}
\hline \multirow{3}{*}{ CHARACTERISTICS } & \multicolumn{3}{|c|}{ KNOWLEDGE LEVEL } & \multicolumn{3}{|c|}{ ATTITUDE LEVEL } & \multicolumn{3}{|c|}{ PRACTICE LEVEL } \\
\hline & \multirow{2}{*}{$\begin{array}{l}\text { Good } \\
\text { n (\%) }\end{array}$} & \multirow{2}{*}{$\begin{array}{l}\text { Poor } \\
\text { n (\%) }\end{array}$} & \multirow{2}{*}{ p-value } & \multirow{2}{*}{$\begin{array}{l}\text { Good } \\
\text { n (\%) }\end{array}$} & \multirow{2}{*}{$\begin{array}{l}\text { Poor } \\
\text { n (\%) }\end{array}$} & \multirow{2}{*}{ p-value } & \multirow{2}{*}{$\begin{array}{l}\text { Good } \\
\text { n (\%) }\end{array}$} & \multirow{2}{*}{$\begin{array}{l}\text { Poor } \\
\text { n (\%) }\end{array}$} & \multirow{2}{*}{ p-value } \\
\hline & & & & & & & & & \\
\hline \multicolumn{10}{|l|}{ AGE (YEARS) } \\
\hline $50-65$ & $221(92.5)$ & $18(7 \cdot 5)$ & ${ }^{*} 0.003$ & $64(26.8)$ & $175(73.2)$ & ${ }^{*} 0.001$ & $94(26.6)$ & $259(73.4)$ & 0.640 \\
\hline$>65$ & $145(82.9)$ & $30(17.1)$ & & $24(13.7)$ & $151(86.3)$ & & 18(29.5) & $43(70.5)$ & \\
\hline \multicolumn{10}{|l|}{ SEX } \\
\hline Male & $129(89.0)$ & 16(11.0) & 0.794 & $30(20.7)$ & $115(79 \cdot 3)$ & 0.836 & $39(26.9)$ & $106(73.1)$ & $0.95^{8}$ \\
\hline Female & $237(88.1)$ & $32(11.9)$ & & $58(21.6)$ & $211(78.4)$ & & $73(27.1)$ & 196(72.9) & \\
\hline \multicolumn{10}{|l|}{ MARITAL STATUS } \\
\hline Single & $43(87.8)$ & $6(12.2)$ & 0.880 & $12(24 \cdot 5)$ & $37(75 \cdot 5)$ & 0.556 & $10(20.4)$ & $39(79.6)$ & 0.400 \\
\hline Married & $323(88.5)$ & $42(11.5)$ & & $76(20.8)$ & $289(79.2)$ & & $102(27 \cdot 9)$ & $263(72.1)$ & \\
\hline \multicolumn{10}{|l|}{ EDUCATION } \\
\hline Primary school & $265(85.5)$ & $45(14 \cdot 5)$ & ${ }^{*} 0.001$ & $52(16.8)$ & $258(83.2)$ & ${ }^{*}<0.001$ & $85(27.4)$ & $225(72.6)$ & 0.928 \\
\hline $\begin{array}{c}\text { High school and } \\
\text { above }\end{array}$ & $101(97.1)$ & $3(2.9)$ & & $36(34.6)$ & $68(65.4)$ & & $27(26.0)$ & $77(74.0)$ & \\
\hline \multicolumn{10}{|l|}{ OCCUPATION } \\
\hline Unemployed & $124(90.5)$ & $13(9 \cdot 5)$ & 0.347 & $21(15 \cdot 3)$ & $116(84 \cdot 7)$ & *0.038 & $38(29.0)$ & $93(71.0)$ & 0.536 \\
\hline Employed & $242(87.4)$ & $35(12.6)$ & & $67(24.2)$ & $210(75.8)$ & & $74(26.1)$ & $209(73.9)$ & \\
\hline \multicolumn{10}{|c|}{ NUMBER OF HOUSEHOLD MEMBERS } \\
\hline$<5$ & $221(87.0)$ & $33(13.0)$ & 0.263 & $50(19 \cdot 7)$ & $204(80.3)$ & 0.325 & $75(29.5)$ & 179(70.5) & 0.153 \\
\hline$\geq 5$ & $145(90.6)$ & $15(9.4)$ & & $38(23.8)$ & $122(76.2)$ & & $37(48.7)$ & $39(51.3)$ & \\
\hline
\end{tabular}

Table 5. Associations between general characteristics and knowledge, attitude and practice regarding eye problems $(n=414)$ 


\begin{tabular}{|c|c|c|c|}
\hline \multirow{3}{*}{ RISK FACTORS } & \multicolumn{3}{|c|}{ PRESENCE OF EYE PROBLEMS } \\
\hline & Yes & No & \multirow[t]{2}{*}{ p-value } \\
\hline & n (\%) & n (\%) & \\
\hline \multicolumn{4}{|l|}{ UNDERLYING DISEASE } \\
\hline Yes & 168(90.3) & $18(9.7)$ & 0.271 \\
\hline No & $198(86.8)$ & $30(13.2)$ & \\
\hline \multicolumn{4}{|c|}{ EXCESSIVE SUNLIGHT EXPOSURE } \\
\hline Yes & $196(87.9)$ & $27(12.1)$ & 0.724 \\
\hline No & $170(89.0)$ & $21(11.0)$ & \\
\hline \multicolumn{4}{|l|}{ SMOKING } \\
\hline Yes & $81(95 \cdot 3)$ & $4(4.7)$ & *0.026 \\
\hline No & $285(86.6)$ & $44(13.4)$ & \\
\hline \multicolumn{4}{|l|}{ HISTORY OF EYE INJURY } \\
\hline Yes & $97(85.1)$ & $17(14.9)$ & 0.194 \\
\hline No & $269(89.7)$ & $31(10.3)$ & \\
\hline \multicolumn{4}{|l|}{ ALCOHOL DRINKING } \\
\hline Yes & $25(96.2)$ & $1(3.8)$ & 0.202 \\
\hline No & $341(87.9)$ & $47(12.1)$ & \\
\hline
\end{tabular}

Table 6. Associations between risk factors of eye problems and presence of eye problems $(n=414)$

\begin{tabular}{|c|c|c|c|}
\hline \multirow{3}{*}{ DESCRIPTIONS } & \multicolumn{3}{|c|}{ PRESENCE OF EYE PROBLEMS } \\
\hline & Yes & No & p-value \\
\hline & n (\%) & n (\%) & \\
\hline \multicolumn{4}{|l|}{ KNOWLEDGE LEVEL } \\
\hline Good & $326(89.1)$ & $40(10.9)$ & 0.243 \\
\hline Poor & $40(83.3)$ & $8(16.7)$ & \\
\hline \multicolumn{4}{|l|}{ ATTITUDE LEVEL } \\
\hline Good & $78(88.6)$ & $10(11.4)$ & 0.939 \\
\hline Poor & $288(88.3)$ & $38(11.7)$ & \\
\hline \multicolumn{4}{|l|}{ PRACTICE LEVEL } \\
\hline Good & $105(93.8)$ & $7(6.2)$ & *0.039 \\
\hline Poor & $261(86.4)$ & $41(13.6)$ & \\
\hline
\end{tabular}

Table 7. Associations between knowledge, attitude and practice, and presence of eye problems $(n=414)$

drastically significant between them at $\mathrm{p}$ value $<0.05$.

\begin{tabular}{|l|c|c|c|c|}
\multirow{2}{*}{ DESCRIPTIONS } & \multicolumn{2}{c}{ ATTITUDE } & \multicolumn{2}{c|}{ PRACTICE } \\
& $\mathbf{r}$ & $\begin{array}{c}\mathbf{p}- \\
\text { value }\end{array}$ & $\mathbf{r}$ & $\begin{array}{c}\mathbf{p}- \\
\text { value }\end{array}$ \\
\hline KNOWLEDGE & 0.0406 & 0.408 & 0.0458 & 0.494 \\
\hline ATTITUDE & & & -0.0435 & 0.515 \\
\hline
\end{tabular}

Table 8. Correlations between Knowledge, attitude and Practice $(\mathrm{n}=414)$

\section{DISCUSSION}

Nearly half of the older people suffered from cataract (40.8\%) as leading eye problem in the community. This result was similar to a study in India. ${ }^{10}$ Refractive error was found to be second major eye problem $(27.3 \%)$ followed by pterygium (12.8\%). Surprisingly, $91.3 \%$, out of 414 older people suffered at least one kind of eye problems. Although the prevalence of eye problems was quite high, most risk factors of eye problems have no significant association with eye problems except smoking. About half of older people (50.2\%) had no underlying diseases such as 
cardiovascular disease, diabetes and hypertension which can lead to eye problems. $53.9 \%$ of respondents had excessive exposure to sunlight. Considering about eye injury, only $27.5 \%$ of older people had experience to eye injury. Though only $20.5 \%$ of respondents had smoking habit, 81 out of 85 older people who had smoking habit suffered eye problems, and there was also statistically significant association between smoking and presence of eye problems ( $\mathrm{p}$ value $=0.026$ ) at $\mathrm{p}$-value $<0.05$. It was confident according to similar study. ${ }^{11}$

Knowledge level was quite high as $88.4 \%$ of older people had good knowledge. The result was nearly the same with other study. ${ }^{12}$ However, attitude and practice levels were substantially low percentages as only $21.3 \%$ of respondents had good level of attitude and only $27.3 \%$ had good practice. The results were confident with other studies.13,14 This might be explained by some reasons; (a) difficult access to diagnosis and treatment services, (b) doubtful health education curriculums by ministry, (c) cultural beliefs, and information, education and communication (IEC) materials distributed by other organizations. ${ }^{15}$ Therefore, effective health education system from ministry of health and sports, strengthening eye care program from International Non-Governmental Organizations (INGO), Local Non-Governmental Organizations (NGO) and very informative mass media are punctually desired in the study area.

Distinctly, $88.4 \%$ of older people showed a good level of knowledge, even though they are living in rural area and $74.9 \%$ of older people had primary education level. This can be explained as community people can access easily to all education media and the effectiveness of interventions implemented by government and other partners also seem to have some impact. There were significant associations between age $(\mathrm{p}=\mathrm{o.003})$, education status $(\mathrm{p}=\mathrm{o.001})$ and knowledge level of respondents. Education status was also associated with knowledge of eye problems in different study in India. ${ }^{16}$ Older group of age had less percentage on knowledge level as they retired or took rest from their work and might reduce their interest. Among the respondents who had good knowledge level, $74.9 \%$ were primary education level. Among the older people, only $21.8 \%$ showed good attitude level. This might be occurred even they have good knowledge on eye problems because of cultural belief and wrong perception that eye problems were due to old age. Meanwhile, there were significant associations between age $(\mathrm{p}=\mathrm{o.001})$, education status (p<0.001), occupation status (0.038) and attitude level. This may imply that older people with high school and above level of education had more good attitude level. Moreover, among older people who had <500,0oo kyats of monthly family income, only $17.2 \%$ had good attitude level which was similar with a study in China. ${ }^{17}$

Contrastingly, only $\mathbf{2 7 . 1} \%$ of older people had good practice level. This might be due to poor access to eye care services and financial problems. ${ }^{8}$ It was significantly low and considerable, that might be needed more new kind of interventions to improve eye diseases screening programs and eye care seeking behaviours. Although there was no significant association between socioeconomic factors and practice level, this can be considered as their eye care seeking practices should be improved whatever they have different kinds of socioeconomic status. ${ }^{19,20}$

About associations between risk factors of eye problems and presence of eye problems, only smoking $(\mathrm{p}=\mathrm{0.026})$ had significant association with presence of eye problems. Among 85 older people who had smoking habit, 81 people $(96.4 \%)$ occurred eye problems. Moreover, there were no significant associations between knowledge, and attitude, and presence of eye problems at $\mathrm{p}$-value $<0.05$. However, practice level was significantly associated with presence of eye problems at $\mathrm{p}$-value $=0.039$. This can be explained that although knowledge, attitude and practice on eye problems were important factors, other risk factors like smoking status can also be considered in addressing eye problems. ${ }^{21-23}$

About correlations among knowledge, attitude and practice, the results revealed that there was a negative association between attitude and practice, which means that even improving attitude level, practice will still remain or straightly tend to poor. However, there was positive association between knowledge and practice level and it showed that if older people had more familiar with information on eye diseases or eye problems, their practice are going to improve. ${ }^{24,25}$ Therefore, it seems that new interventions should be focused separately on each part. However, there was no statistical significance between knowledge, attitude, and practice at $\mathrm{p}$ - 
value $<0.05$

\section{CONCLUSION}

The study noticed that higher prevalence of eye problems with relatively poor level of care seeking practice and unawareness on risk factors in targeted community. The results of the study provided for closing the disparity in the primary eye care intervention of public health concern. Knowledge and awareness for changing attitude about eye problems, health seeking behavior and preventive practices should be accomplished more in the community and implementation of primary eye care training for community health volunteers, enhancing eye health education program at each level including primary care unit level should be reviewed and applied to empower people. According to the results of this study, community development programs, like improving access to eye care services and community support programs for those who had financial problems should also be considered as essential intervention programs. Finally, it is recommended as further area of research to conduct research following interventional community based action research.

Acknowledgement: This research was financially supported by the goth Anniversary of Chulalongkorn University, Rachadapisek Sompote Fund.

\section{REFERENCES}

1. World Health Organization. Blindness and Vision Impairment Prevention. Geneva: World Health Organization; 2018 [cited 2018 November 13]. Available from: http://www.who.int/blindness/causes/priority/en/

2. World Health Organization. Improving Eye Health in Myanmar: National Action Plan 2016-2020. Geneva: World Health Organization; 2018 [cited 2018 November 12]. Available from: http://www.searo.who.int/myanmar/areas/ncd eyehe althinmyanmar/en/

3. Ministry of Health and Sports, The Republic Union of Myanmar. Report of Rapid Assessment of Avoidable Blindness Survey-2018.

4. Arie YN, Pinhas N, Geoff C, Gina S, Gerald S, Richard R. Causes of blindness in rural Myanmar (Burma): Mount Popa Taung-Kalat Blindness Prevention Project. Clinical Ophthalmology. 2009;3: 413-21.

5. Ministry of Health, Myanmar. Health in Myanmar 2014 [Internet]. MOH Publication; 2014 [Cited 2015 Feb 3]. Available from: http://www.moh.gov.mm/
6. Wong TY, Loon SC, Saw SM. The epidemiology of age related eye diseases in Asia. Br J Ophthalmol. 2006;90:506-11.

7. The Department of Health, Australian Government. Possible Risk Factors for Eye Diseases, 2008. [cited 2018 November 13]

8. Casson RJ, Newland HS, Muecke J, et al. Prevalence and causes of visual impairment in rural Myanmar: the Meiktila Eye Study. Ophthalmology. 2007;114:2302-8.

9. Chow S-C, Shao J, Wang H. Sample Size Calculation in Clinical Research. 2008. Chapman \& Hall/CRC., 83 P.

10. Praveen V, Badrinath T, Madhurjya G, Giovanni M, Monica C, Ravilla D. Prevalence of Cataract in an Older Population in India: The India Study of Agerelated Eye Disease. Ophthalmology. 2011 Feb; 118(219): 272-8.e2.

11. Sannapaneni K, Kovai V, Bindiganavale R. S, Gullapalli N. R, Ravi T, Dorairajan B. Smoking and Its Association with Cataract: Results of the Andhra Pradesh Eye Disease Study from India. Invest. Ophthalmol. Vis. Sci.2005;46(1):58-65.

12. Kukuh N, David M, Ken B, Paul C. Awareness of eye diseases and risk factors: identifying needs for health education and promotion in Canada, Canadian Journal of Ophthalmology 2006;41(5):617-23.

13. Khandekar R, Al-Harby S. Knowledge and attitude for eye diseases and satisfaction for services among urban citizens of Oman: A pilot study. Oman Journal of Ophthalmology 2008;1(1):13-7.

14. Graham JE, McGilligan VE, Berrar D, Leccisotti A, Moore JE, Bron AJ, Moore TCB. Attitudes towards Diagnostic Tests and Therapies for Dry Eye Disease. Ophthalmic Res 2010; 43:11-17.

15. Akbar F, Hassan H, Kazem M. Eye care utilization patterns in Tehran population: a population based cross-sectional study. BMC Ophthalmology 2006; 6: 4 .

16. Dandona R, Dandona L, John RK, McCarty CA, Rao GN. Awareness of eye diseases in an urban population in southern India. Bulletin of the World Health Organization. 2001;79(2):96.

17. Tang Y, Wang X, Wang J, Jin L, Huang W, Luo Y, Lu Y. Risk factors of age-related cataract in a Chinese adult population: the Taizhou Eye Study. Clinical \& experimental ophthalmology. 2018 May;46(4):371-9. 18. Ahmad K, Zwi AB, Tarantola DJ, Chaudhry TA. Self-perceived barriers to eye care in a hard-to-reach population: the Karachi Marine Fishing Communities Eye and General Health Survey. Investigative ophthalmology \& visual science. 2015;56(2):102332. 
19. Hwang J, Rudnisky C, Bowen S, Johnson JA. Socioeconomic factors associated with visual impairment and ophthalmic care utilization in patients with type II diabetes. Canadian Journal of Ophthalmology/Journal Canadien d'Ophtalmologie. 2015;50(2):119-26.

2o.Islam FM, Chakrabarti R, Islam SZ, Finger RP, Critchley C. Factors associated with awareness, attitudes and practices regarding common eye diseases in the general population in a Rural District in Bangladesh: the Bangladesh population-based diabetes and eye study (BPDES). PLoS One. 2015;10(7):e0133043.

21. Scott AW, Bressler NM, Ffolkes S, Wittenborn JS, Jorkasky J. Public attitudes about eye and vision health. JAMA ophthalmology 2016;134(10):1111-8.

22. Islam FM, Chakrabarti R, Dirani M, Islam MT, Ormsby G, Wahab M, Critchley C, Finger RP. Knowledge, attitudes and practice of diabetes in rural
Bangladesh: the Bangladesh population based diabetes and eye study (BPDES). PLoS One. 2014;9(10):e110368.

23. Thapa R, Bajimaya S, Paudyal G, Khanal S, Tan S, Thapa SS, van Rens G. Population awareness of diabetic eye disease and age related macular degeneration in Nepal: the Bhaktapur Retina Study. BMC ophthalmology. 2015;15(1):188.

24. Srinivasan NK, John D, Rebekah G, Kujur ES, Paul P, John SS. Diabetes and Diabetic Retinopathy: Knowledge, Attitude, Practice (KAP) among Diabetic Patients in A Tertiary Eye Care Centre. Journal of clinical and diagnostic research: JCDR 2017;11(7):NCo1.

25. Habiba U, Ormsby GM, Butt ZA, Afghani T, Asif M. Knowledge and practices of teachers associated with eye health of primary school children in Rawalpindi, Pakistan. Taiwan Journal of Ophthalmology 2017;7(1):28-33.
Conflict of interest: None declared

\section{AUTHOR AFFILIATIONS:}

1. College of Public Health Sciences, Chulalongkorn Universiy, Bangkok, 10330, Thailand

2. Department of Public Health, Ministry of Health and Sports, Naypyitaw, 15032, Myanmar

3. 200-Bedded Hospital, Pyinmana, 15012, Myanmar

\section{Cite this article as:}

Ko KK, Pumpaibool T, Wynn MMM, Win Y, Aung PL, Kyi TM. Prevalence and Risk Factors of Eye Problems among Older People in Central Tropical Region, Naypyitaw Union Territory, Myanmar. Int Healthc Res J. 2019;3(2):68-75. doi: 10.26440/IHRJ/0302.05.521080

\section{*Corresponding Author:}

Tepanata Pumpaibool

College of Public Health Science

Chulalongkorn University

Bangkok, 10330, Thailand
For article enquiry/author contact details, e-mail at: editor.ihri@gmail.com, editor@ihrjournal.com 